\title{
Condições de ambiente favoráveis à germinação e à infecção de Puccinia substriata var. penicillariae em diferentes cultivares de milheto pérola
}

\author{
Antonio Carlos T. Costa ${ }^{1}$, Aldir O. Carvalho ${ }^{1}$, Dartanhã J. Soares ${ }^{2}$, \\ Margarida Goréte F. Carmo $^{1}$ \& Carlos Pimentel $^{1}$
}

\begin{abstract}
${ }^{1}$ Departamento de Fitotecnia, Instituto de Agronomia, Universidade Federal Rural de Rio de Janeiro, CEP 23890-000, Seropédica, RJ, Brasil; ' 2Departamento de Fitopatologia, Universidade Federal de Viçosa, CEP 36570-000, Viçosa, MG, Brasil, e-mail: gorete@ufrrj.br
\end{abstract}

Autor para correspondência: Margarida Goréte F. Carmo

COSTA, A.C.T., CARVALHO, A.O., SOARES, D.J., CARMO, M.G.F. \& PIMENTEL, C. Condições de ambiente favoráveis à germinação e à infecção de Puccinia substriata var. penicillariae em diferentes cultivares de milheto pérola. Fitopatologia Brasileira 32:400-407. 2007

\begin{abstract}
RESUMO
A ferrugem do milheto (Pennisetum glaucum), causada por Puccinia substriata var. penicillariae, provoca perdas na produção da forragem. Tendo em vista a escassez de informações sobre a doença no Brasil realizou-se o presente trabalho sobre a sua epidemiologia. Avaliaram-se, em casa-de-vegetação, o período latente médio, a freqüência de infecção e tamanho das lesões da ferrugem em quatro genótipos de milheto: ENA 1, Composto II, BRS 1501 e HKP. In vitro, monitorou-se a germinação dos urediniósporos em diferentes temperaturas $\left(10,15,20\right.$ e $\left.25^{\circ} \mathrm{C}\right)$, na presença ou não de luz. Após isto, avaliou-se o processo de infecção nos genótipos Guerguera, Souna III, BRS 1501 e ENA 1, em câmara de crescimento, utilizando-se $0,1,2,4,8$ e 12 h de molhamento foliar, na presença ou não de luz, e em casa-de-vegetação, nos genótipos ENA 1, Guerguera e Souna III, utilizando-se 3/4, 1, 2, 4, 6 e 8 h de molhamento foliar. O período latente médio da ferrugem do milheto variou entre 10 e 12 dias, e os urediniósporos germinaram em faixa ampla de temperatura, de $10^{\circ} \mathrm{C}$ a $25^{\circ} \mathrm{C}$, na presença ou não de luz, com germinação máxima a $17,5^{\circ} \mathrm{C}$ no escuro. Nestas condições, os primeiros esporos germinaram com menos de 45 min. e atingiram taxa máxima, 88,2\%, em 1,7 h de incubação. Infecções de folhas foram observadas em plantas submetidas a apenas 45 min de molhamento foliar após a inoculação, porém, com efeito benéfico do escuro e do aumento do período de molhamento foliar.
\end{abstract}

Palavras-chave adicionais: Etiologia, epidemiologia, ambiente, molhamento foliar.

\begin{abstract}
Optimal environmental conditions for induction of germination and infection of Puccinia substriata var. penicillariae in different pearl millet cultivars

The rust caused by Puccinia substriata var. penicillariae in Pearl millet (Pennisetum glaucum) induces yield losses in this forage crop. Considering the lack of information about this disease in Brazil, this research on its epidemiology has been carried out. The mean latency period, the frequency of infection process and size of lesions on four genotypes of pearl millet (Pennisetum glaucum) ENA 1, Composto II, BRS 1501 and HKP were evaluated in the greenhouse. In vitro, the germination of the urediniospores was monitored at different temperatures $\left(10,15,20\right.$ and $\left.25^{\circ} \mathrm{C}\right)$, with or without light. After this, the infection process was compared for the genotypes Guerguera, Souna III, BRS 1501 and ENA 1, in a growth chamber, with the leaf wetting time of $0,1,2,4,8$ and 12 hours, with or without light, and in greenhouse, on the genotypes ENA 1, Guerguera and Souna III, with the leaf wetting times of 3/4, 1, 2, 4, 6 and 8 hours. A mean latency period for pearl millet rust between 10 and 12 days was shown, and the urediniospores germinated in a wide range of temperatures, from 10 to $25^{\circ} \mathrm{C}$, with or without light, with a maximum germination at $17.5^{\circ} \mathrm{C}$ in the dark. In these conditions, the germination of first spores initiated for less than 45 min at a maximum percentage of $88.2 \%$, with $1.7 \mathrm{~h}$ of incubation. Leaf infection can also start after 45 min of leaf wetting after inoculation, but there is a beneficial effect of dark and longer leaf wetting time.
\end{abstract}

Additional keywords: Etiology, epidemiology, environment, leaf wetting.

\section{INTRODUÇÃO}

O milheto pérola [Pennisetum glaucum (L.) R. Brown] vem sendo utilizado no Brasil para a produção

Parte da tese de Doutorado do primeiro autor. Universidade Federal Rural de Rio de Janeiro. Seropédica RJ. 2005. de palhada no sistema de plantio direto no cerrado (Lopes, 1997; Pimentel, 2002), produção de forragem para pastejo ou silagem, e para a produção de grãos usado na fabricação de rações animais (Netto, 1998; Costa et al. 2005), principalmente em cultivos no período da seca. A cultura é de fácil instalação e requer poucos insumos, pois a planta tem um sistema radicular profundo e vigoroso, apresenta alta eficiência no uso da água e adaptação a solos de baixa 
fertilidade (Norman et al., 1995; Pereira Filho et al., 2003; Costa et al., 2006). Por estas características, é o principal cereal cultivado para alimentação humana e animal nos trópicos semiáridos da África e da Índia, constantemente sujeitos à seca, altas temperaturas e deficiência de nutrientes (Payne, 2000). Entre os fatores responsáveis pela redução na produção de matéria seca, encontram-se as doenças, principalmente a ferrugem (Puccinia substriata Ell. \& Barth. var. penicillariae (Speg.) Ramachar \& Cumm.) (Carvalho et al., 2006). Os danos causados por esta doença podem resultar em perdas de até $76 \%$ da produção de grãos (Wilson et al., 1996) e em redução da qualidade da forragem (Wilson et al., 1994). No Brasil, os sintomas de ferrugem nas folhas de milheto foram inicialmente observados em 1997, em área experimental da Embrapa-Cerrados e em lavouras comerciais do Distrito Federal e municípios vizinhos de Minas Gerais e Goiás (Charchar \& Anjos, 2000) e, em 1999 em área experimental no campus da UFRRJ, Rio de Janeiro (Carvalho et al., 2006).

Tendo em vista a expansão da cultura no Brasil, os danos que a ferrugem pode causar à mesma e a escassez de informações sobre o patossistema milheto $\mathrm{x} P$. susbstriata var. penicillariae, estudos básicos na área de epidemiologia e de controle da doença são necessários. Um dos primeiros aspectos que precisa ser investigado é o efeito das condições de ambiente, como temperatura, luz e molhamento foliar, sobre o processo de infecção e progresso da doença e a existência de variabilidade genética na população hospedeira. Estas informações poderão, posteriormente, ser utilizadas em ensaios que envolvam inoculação de plantas e realização de testes em condições controladas (Tapsoba \& Wilson, 1997), e no desenvolvimento de cultivares resistentes. Estas informações permitirão, ainda, compreender melhor a epidemiologia da doença e facilitarão estabelecer estratégias de controle.

A temperatura e a luz são citadas por vários autores como fatores críticos para a germinação dos esporos de ferrugens e subseqüente infecção de seus respectivos hospedeiros (Huber e Gillespie, 1992; Kramer \& Eversmeyer, 1992; Vallavielle-Pope et al., 2000). Tapsoba e Wilson (1997) citam que a germinação dos urediniósporos de Puccinia substriata Ellis \& Barth. var. indica Ramachar \& Cumm., descrita como agente etiológico da ferrugem do milheto nos EUA e Índia, é maior à temperatura de 19 a $22^{\circ} \mathrm{C}$, quando atinge $90 \%$ em um período de seis a sete horas e, que esta pode ser parcialmente inibida pela presença de luz. Para P. striiformis Westend. f. sp. hordei Erichs \& Henn., a temperatura ótima para a germinação dos urediniósporos situa-se na faixa entre 9 a $15^{\circ} \mathrm{C}$ (Brown Jr. et al., 2001). Além da predominância de temperaturas favoráveis, a ocorrência de molhamento foliar também é um fator essencial para a germinação dos esporos e penetração no tecido hospedeiro. Para Puccinia recondita Rob. \& Desm. f.sp. tritici Ericks. \& Henn. e Puccinia striiformis Westend., o número mínimo de horas de molhamento foliar para germinação dos urediniósporos e penetração nos tecidos da planta de trigo (Triticum aestivum L.) são de três a seis horas sob condições ótimas de temperatura (Huber \& Gillespie, 1992; Vallavielle-Pope et al., 2000), enquanto que para $P$. striiformis f. sp. hordei são necessários pelo menos três horas contínuas de molhamento foliar para que ocorra germinação e infecção de plantas de cevada (Hordeum vulgare L.) (Brown Jr. et al., 2001).

Existem relatos de resistência parcial de milheto à ferrugem, causada por P. substriata var. indica (Wilson et al., 1994; Wilson, 1997), assim como em vários outros cereais, em geral expressa pela redução do número e tamanho das lesões e, ou, aumento do período latente (Wilson \& Gates, 1999; DíazLago et al., 2003), não existindo porém informações para o patossistema milheto $\mathrm{x}$ P. substriata var. penicillariae.

Diante do exposto, e tendo em vista a expansão do cultivo de milheto e a ocorrência severa da ferrugem no cultivo no período da seca e a necessidade de se desenvolverem pesquisas e estratégias de controle da doença, realizou-se o presente trabalho com o objetivo de se determinar o período de incubação, o período latente médio, a freqüência de infecção, o tamanho das lesões da ferrugem do milheto, o efeito da luz e temperatura sobre a germinação de urediniósporos do patógeno, 'in vitro', bem como o efeito das condições de ambiente sobre o processo de infecção e desenvolvimento da doença em genótipos de milheto.

\section{MATERIAL E MÉTODOS}

\section{Caracterização inicial da ferrugem em quatro genótipos de milheto}

Para caracterizar o progresso da ferrugem do milheto, realizou-se o primeiro experimento em agosto de 2001, em casa-de-vegetação do Departamento de Fitotecnia da UFRRJ. Foram utilizados quatro genótipos de milheto pérola, sendo um de origem africana (HKP) e três de origem brasileira (BRS 1501, ENA 1 e Composto II). O ENA 1 e o Composto II (4 geração) foram obtidos por meio do cruzamento natural de três genótipos africanos (HKP, Souna III e Guerguera), sendo que o ENA 1 foi selecionado para a época das águas e o composto II selecionado para a época da seca (Geraldo, 2002). As sementes dos genótipos africanos foram cedidas através de um convênio da UFRRJ com o Centre d'Etude Régional pour I'Amériolation de I'Adaptation à la Sécheresse (CERAAS, Bambey, Senegal). O genótipo brasileiro (BRS 1501) foi fornecido pelo Centro Nacional de Pesquisa de Milho e Sorgo, da EMBRAPA, em Sete Lagoas, Minas Gerais, Brasil. O solo utilizado no experimento foi um planossolo, e o plantio foi feito em potes de 21 contendo uma planta por pote, em casa-de-vegeação. $\mathrm{O}$ delineamento experimental utilizado foi o inteiramente casualizado, com quatro tratamentos e 12 repetições, representadas por uma planta cada. Aos 22 dias após a semeadura, as plantas foram inoculadas, por meio de atomização, nas faces dorsal e ventral das folhas até o ponto de escorrimento, utilizando-se urediniósporos coletados em plantas naturalmente infectadas no campo, em suspensão contendo $4 \times 10^{5}$ urediniósporos $\mathrm{mL}^{-1}$ de água, com uma gota de 'tween' 80 por litro. No período compreendido entre a inoculação e o final do experimento, a temperatura variou de 18 a $37^{\circ} \mathrm{C}$.

As avaliações foram feitas na quarta folha (basal), considerando uma área de $5,0 \mathrm{~cm}^{2}$ situada nos $2 / 3$ terminais 
desta. Para avaliar a freqüência de infecção (número de pústulas em $5,0 . \mathrm{cm}^{-2}$ ), realizaram-se contagens diárias das pústulas, prosseguindo até o momento em que não se observou mais o aparecimento de novas pústulas, o que ocorreu aos 18 dias. O tamanho das pústulas (TP) foi determinado nas mesmas folhas em que foi avaliada a freqüência de infecção. Mediram-se o comprimento e a largura de 12 pústulas por planta, com auxílio de um paquímetro. A área de cada pústula foi calculada utilizandose a fórmula: $\mathrm{TP}=$ comprimento $\mathrm{x}$ largura das pústulas, expresso $\mathrm{em}^{\mathrm{mm}^{2}}$. Determinou-se, inicialmente, o número de dias para aparecimento dos sintomas, tendo como base o tempo médio para aparecimento das primeiras pústulas em cada uma das plantas, e o período latente médio (PLM), caracterizado pelo número de dias para surgimento de $50 \%$ das pústulas totais, tendo como base o número máximo de pústulas esporulantes. Determinou-se, ainda, a porcentagem de plantas infectadas por tratamento, considerando as 12 plantas inoculadas por tratamento.

\section{Determinação dos requerimentos para germinação dos urediniósporos e início do processo de infecção}

No laboratório, realizaram-se dois ensaios. No primeiro, realizado em agosto de 2003, avaliaram-se o tempo e as condições de temperatura e de luz para a germinação dos urediniósporos. Os esporos foram coletados com auxílio de pincel, a partirde folhas de plantas de milhetopérolanaturalmente infectadas no campo. A seguir, foi preparada suspensão de esporos em água destilada e esterilizada, contendo uma gota de 'tween' 80 por $1\left(10^{5}\right.$ urediniósporos. $\left.\mathrm{mL}^{-1}\right)$. Alíquotas de $10 \mathrm{~mL}$ desta suspensão foram adicionadas a tubos de ensaio, e estes foram acondicionados e mantidos em diferentes condições de ambiente: luz e escuro, e temperaturas de 10, 15, 20 e $25^{\circ} \mathrm{C}$, em arranjo fatorial $2 \times 4$. Adotou-se o delineamento inteiramente casualizado e três repetições por tratamento, representadas por um tubo cada. As leituras foram efetuadas após 2,4 e $6 \mathrm{~h}$ de incubação nas respectivas condições, por meio de contagem do número de urediniósporos germinados (tubo germinativo igual a duas vezes o diâmetro do esporo) em um total de 100 esporos por cada tubo ou parcela. Os dados, expressos em porcentagem, foram submetidos à análise de variância e de regressão, para descrição do efeito da temperatura sobre a germinação. A temperatura ideal para germinação dos urediniósporos foi determinada pelo cálculo do ponto de máximo das curvas. No segundo ensaio, realizado para avaliar a velocidade de germinação dos urediniósporos, utilizou-se a mesma metodologia do primeiro bioensaio e a melhor condição de temperatura e de luz, estabelecida no mesmo. As observações iniciaram-se aos 15 min após a montagem do teste e seguiram-se aos 30, 45, 60, 90, 120, 240 e 360 min, além de mais duas avaliações, às 20 e 30 horas de incubação. Os dados de germinação, em função do período de incubação, foram submetidos à análise de regressão e ajuste por diferentes modelos e apresentados graficamente.

Os requerimentos de luz e de horas de molhamento foliar para início do processo de infecção da folha foram avaliados em outros dois ensaios, um em câmara de crescimento e outro, em casa-de-vegeação. No primeiro, utilizaram-se plantas com 21 dias de idade dos genótipos Guerguera, Souna III, BRS 1501 e ENA 1. Após a inoculação por atomização, as plantas foram submetidas à câmara úmida utilizando-se plásticos transparentes ou de cor preta, de modo a manter diferentes períodos de molhamento foliar $(0,1,2,6$ e $12 \mathrm{~h}) \mathrm{e}$ a presença ou não de luz, respectivamente. As plantas foram mantidas em condições de câmara de crescimento, regulada para $18 \pm 1^{\circ} \mathrm{C}$ e $12 \mathrm{~h}$ de fotoperíodo. Adotou-se o delineamento de blocos ao acaso com seis repetições, representadas por duas plantas cada. Os tratamentos foram arranjados em esquema fatorial $2 \times 4 \times 5$. As avaliações foram efetuadas aos 15 dias após a inoculação, quando foi feita a contagem do número de pústulas por unidade de área foliar e a determinação da área foliar lesionada, obtida pela razão entre o produto do número de lesões e área média das lesões pela área total da folha.

No segundo ensaio, realizado durante os meses de junho e julho de 2004 em condições de casa-de-vegeação, avaliaram-se os requerimentos de horas de molhamento foliar para início do processo de infecção da folha, utilizando-se as cultivares ENA 1, Guerguera e Souna III. Foram utilizadas plantas com 18 dias de idade e uma suspensão contendo $4 \times 10^{5}$ urediniósporos. $\mathrm{mL}^{-1}$. Após a inoculação por atomização, as plantas foram submetidas à câmara úmida feita com auxílio de plástico transparente, de modo a manter diferentes períodos de molhamento foliar $(0,75,1,0,2,0,4,0,6,0$ e $8,0 \mathrm{~h})$. Adotou-se o delineamento inteiramente casualizado, em arranjo fatorial $3 \times 6$, e cinco repetições, representadas por quatro plantas cada. Após nove dias de incubação, em condições de casa-de-vegeação, iniciaram-se as quantificações do número de pústulas por unidade de área foliar, prosseguindo-se por mais oito dias. Com as contagens diárias do número de pústulas, para os diferentes tratamentos, calcularam-se os valores da área abaixo da curva de progresso da doença. No período compreendido entre a inoculação e o final do experimento, a temperatura variou de 16 a $42^{\circ} \mathrm{C}$.

Em ambos os ensaios, os dados foram submetidos à análise de variância $(p<0,05)$, teste de Tukey $(p<0,05)$ e análise de regressão, considerando-se as médias das observações, utilizando-se o programa SAEG 8.02.

\section{RESULTADOS E DISCUSSÃO}

\section{Caracterização inicial da ferrugem em quatro genótipos de milheto}

A cultivar ENA 1, selecionada no período das águas, conseqüentemente sem a presença da doença, apresentou os primeiros sintomas aos sete dias após a inoculação, com período latente médio de 10,2 dias e infecção em todas as 12 plantas inoculadas. Comparada às demais, foi a que apresentou maior freqüência de infecção $\left(8,33 \pm 2,21\right.$ pústulas. $\left.5 \mathrm{~cm}^{-2}\right)$ e maior tamanho das lesões $\left(3,5 \pm 0,1 \mathrm{~mm}^{2}\right)$.

A cultivar africana HKP e a nacional BRS 1501 
apresentaram os primeiros sintomas aos sete e oito dias e, período latente médio de 10,9 e 12 dias, respectivamente. Em geral, HKP e BRS 1501 foram semelhantes quanto à freqüência de infecção $\left(4,75 \pm 1,05\right.$ e 4,42 $\pm 1,23$ pústulas. $\left.5 \mathrm{~cm}^{-2}\right)$ e tamanho das lesões $\left(3,3 \pm 0,1 \mathrm{~mm}^{2} \mathrm{e} 3,3 \pm 0,2 \mathrm{~mm}^{2}\right)$. Destes três genótipos, apenas ENA 1 apresentou infecção em 100\% das plantas, enquanto HKP e BRS 1501 apresentaram infecção em 10 $(83,3 \%)$ e $7(58,3)$ das 12 plantas inoculadas, respectivamente, semelhante ao observado por Charchar \& Anjos (2000) para BN 2 e BRS 1501. O Composto II, selecionado no período da seca, conseqüentemente na presença da doença, apresentou menor progresso da doença, sendo as primeiras pústulas observadas a partir do oitavo dia da inoculação, e maior período latente médio, 12,4 dias, e infecção em apenas cinco das 12 plantas inoculadas $(41,7 \%)$. O Composto II apresentou, ainda, menor freqüência de infecção $\left(2,08 \pm 0,48\right.$ pústulas. $\left.5 \mathrm{~cm}^{-2}\right)$ e menor tamanho das lesões, em relação a todos os demais genótipos $\left(2,3 \pm 0,2 \mathrm{~mm}^{2}\right)$.

Com base nestes resultados observados em casade-vegeação pode-se afirmar que existe variabilidade genética entre os genótipos de milheto para resistência à ferrugem. Esta variabilidade precisa, porém, ser avaliada em ensaios mais precisos em condições controladas e no campo, utilizando um maior número de genótipos, para se determinar a magnitude deste efeito sobre o progresso da doença, conforme já comentado por Parlevliet (1979). A importância destes estudos pode ser ainda reforçada pela ausência de relatos sobre resistência quantitativa a $P$. substriata var. penicillariae em milheto. Existem relatos de resistência quantitativa de milheto a $P$. substriata var. indica, expressa pela maior duração do período latente (14,3 dias), e menores dimensões das uredínias $\left(0,02 \mathrm{~mm}^{2}\right)$ no genótipo mais resistente (ICMP 501) contra menor período latente (8,4 dias) e maiores dimensões das uredínias $\left(0,09 \mathrm{~mm}^{2}\right)$ em um dos genótipos mais suscetíveis (Tift 23DB) (Wilson et al., 1994). A diferença entre os genótipos observada por estes autores, bem mais acentuada que a observada no presente estudo, foi confirmada por ensaios em condições de campo, com diferenças altamente significativas entre os dois genótipos. Existem também, para vários outros cereais, relatos de resistência parcial à ferrugem, expressa pela redução da freqüência de infecção e aumento do período latente. Díaz-Lago et al. (2003) relatam, para o patossistema aveia (Avena sativa L.) x P. coronata f. sp. avenae Ericks., período latente de 14,4 dias em duas linhagens com resistência parcial, 4,7 dias superior ao observado em uma cultivar suscetível, e com densidade de uredínias nas duas linhagens equivalente a 44 e $49 \%$ à registrada na cultivar suscetível. Costa (2006), em ensaio de campo no período da seca no município de Seropédica, RJ, com 144 progênies de milheto resultantes de cruzamentos naturais entre as cultivares Souna III, HKP e Guerguera, observou diferenças altamente significativas entre as mesmas quanto à resistência quantitativa a $P$. substriata var. penicillariae, confirmando os resultados obtidos neste ensaio e, a indicação da importância de novos ensaios, com metodologias mais precisas e utilização de genótipos previamente classificados como portadores de maiores níveis de resistência no campo, além de cultivares susceptíveis, para uma melhor caracterização dos componentes de resistência.

\section{Determinação dos requerimentos para germinação dos urediniósporos e início do processo de infecção em plantas de milheto}

Quanto aos requerimentos de temperatura e de luz para a germinação dos urediniósporos, constatou-se que estes germinam rapidamente, independente da presença ou não de luz, apesar desta reduzir significativamente a porcentagem de esporos germinados. Observou-se efeito significativo da temperatura sobre a germinação dos urediniósporos, bem descrita pelo modelo quadrático (Figura 1A). Os esporos germinaram em faixa ampla de temperatura, de 10 a $25^{\circ} \mathrm{C}$, porém com ponto de máximo entre as temperaturas de $15 \mathrm{e}$ $20^{\circ} \mathrm{C}$, ou seja, 17,3 e $17,5^{\circ} \mathrm{C}$ na presença de luz e no escuro, respectivamente. Observou-se, ainda, nos testes em lâmina sob condições ideais, $17,5^{\circ} \mathrm{C}$ e no escuro, que uredinióspros podem germinar com apenas 45 minutos de incubação e atingir a taxa máxima de esporos germinados, $88 \%$, antes de duas horas de incubação (Figura 1B). O efeito do período de incubação sobre a germinação dos urediniósporos foi melhor descrito pelo modelo Linear-Plateau (Alvarez, 1994), que indica o ponto de $1,798 \mathrm{~h}$ como o de máxima germinação de esporos, com $88,2 \%$, determinado pelo ponto de interseção das duas retas (Figura 1B). Estes resultados diferem em parte dos de Tapsoba \& Wilson (1997), que observaram para $P$. substriata var. indica, uma faixa ótima de temperatura para germinação dos urediniósporos, sob vários regimes de luz, entre 19 e $22^{\circ} \mathrm{C}$, com máximo de germinação após seis a sete horas de incubação. Estes autores afirmam também que a presença contínua de luz não inibe, mas retarda o processo de germinação dos esporos, exceto quando é logo seguida pela interrupção da luz ou por fornecimento de pelo menos uma hora de escuro.

Nos ensaios com inoculação em plantas, seguido de incubação na câmara de crescimento, observouse efeito significativo da interação entre luz e cultivar, entre luz e período de molhamento foliar e entre cultivar e período de molhamento foliar sobre o número de pústulas. $\mathrm{cm}^{-2}$ e a severidade da doença (Tabela 1, Figura 2). Na interação entre luz e cultivar, observou-se menor número de pústulas e menor severidade da doença quando as plantas foram mantidas na presença de luz em relação às plantas mantidas no escuro, exceto para a cultivar Souna III. Com relação às cultivares, observou-se, em geral, menor número de pústulas e menor severidade na cultivar Souna III em relação às demais, especialmente à 'Guerguera' (Tabela 1), que se comportaram, respectivamente, como mais resistente e mais suscetível à ferrugem. Da mesma forma, ao se avaliar a interação entre luz e período de molhamento foliar, observaramse maiores freqüências de infecção e maior severidade 

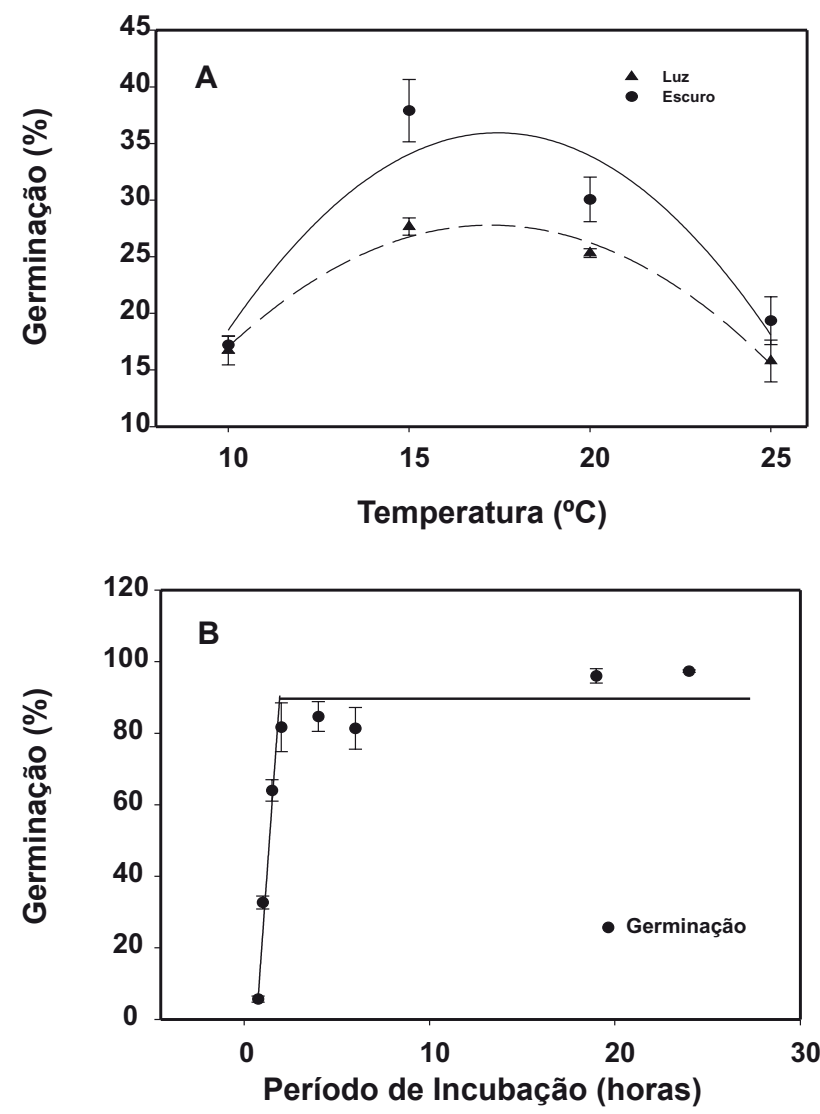

FIG. 1 - Efeito da temperatura e da luz sobre a germinação de urediniósporos de Puccnia substriata var. penicillariae, in vitro, descritas pelo modelo quadrático $\left(\mathrm{Y}_{\text {escuro }}=-59,6225+10,9505 \mathrm{X}\right.$ $\left.0,3137 \mathrm{X}^{2}, \mathrm{r}^{2}=0,939 ; \mathrm{Y}_{\text {luz }}=-33,0930+7,0586 \mathrm{X}-0,2046 \mathrm{X}^{2}, \mathrm{r}^{2}=0,991\right)$ (A), e evolução do processo de germinação a $17,5^{\circ} \mathrm{C}$, no escuro, descrito pelo modelo linear plateau ( $\mathrm{Y}=47,809+75,619 \mathrm{X}, \mathrm{r} 2=0,978)$ e interseção das retas no ponto igual a $\mathrm{x}=1,798$ horas e $\mathrm{y}=88,2 \%$ de germinação (B).

TABELA 1 - Interação entre cultivar e luz sobre a infecção e severidade da ferrugem do milheto, causada por Puccinia substriata var. penicillariae, sob condições de câmara de crescimento

\begin{tabular}{|c|c|c|c|c|}
\hline \multirow[t]{2}{*}{ Cultivar } & \multicolumn{2}{|c|}{ Número de Pústulas.cm ${ }^{-2}$} & \multicolumn{2}{|c|}{ Severidade $\%$} \\
\hline & Luz & Escuro & Luz & Escuro \\
\hline Guerguera & $1,53 \mathrm{~B} \mathrm{a}$ & $2,33 \mathrm{~A} \mathrm{a}$ & $2,99 \mathrm{~B} \mathrm{a}$ & $4,55 \mathrm{~A} \mathrm{a}$ \\
\hline ENA 1 & $0,80 \mathrm{~B} \mathrm{ab}$ & $1,50 \mathrm{~A} \mathrm{ab}$ & $2,81 \mathrm{~B} \mathrm{a}$ & $5,28 \mathrm{~A} \mathrm{a}$ \\
\hline BRS 1501 & $0,70 \mathrm{~B} \mathrm{ab}$ & $1,33 \mathrm{~A} \mathrm{ab}$ & $2,31 \mathrm{~B} \mathrm{a}$ & $4,41 \mathrm{~A} \mathrm{a}$ \\
\hline \multirow[t]{2}{*}{ Souna III } & $0,36 \mathrm{~A} \mathrm{~b}$ & $0,56 \mathrm{~A} \mathrm{~b}$ & $1,52 \mathrm{~A} \mathrm{a}$ & $2,35 \mathrm{~A} \mathrm{~b}$ \\
\hline & \multicolumn{2}{|c|}{25.22} & \multicolumn{2}{|c|}{29,90} \\
\hline
\end{tabular}

${ }^{1}$ Médias seguidas pela mesma letra maiúscula na linha e minúscula na coluna, não diferem entre si a $5 \%$ de probabilidade pelo teste de Tukey.

nas plantas mantidas no escuro, especialmente quando foram fornecidas seis horas de molhamento foliar (Figura 2 A-B). Estes resultados confirmam aqueles obtidos nos testes 'in vitro', onde foi observado redução na porcentagem de germinação dos esporos pela luz, sem que esta necessariamente tenha sido um fator limitante, e estão de acordo com as observações de Eversmeyer (1988) e Rossi et al. (1997) para $P$. recondita f. sp. tritici em trigo. Estes autores citam que a germinação dos urediniósporos na superfície foliar depende das condições de temperatura e de molhamento foliar, podendo ser afetada ou inibida temporariamente pela luz por esta afetar as reações ativadas no início do processo de hidratação dos esporos.

Quanto à interação cultivar $\mathrm{x}$ período de molhamento foliar, observou-se igualmente aumento significativo da freqüência de infecção e da severidade, com o aumento do período de molhamento foliar, e efeitos mais e menos acentuados em 'Guerguera' e 'Souna III', respectivamente, especialmente a partir de $6 \mathrm{~h}$ de molhamento foliar (Figura 2C e 2D), semelhante ao observado no efeito da interação luz $\mathrm{x}$ genótipo descrito na Tabela 1.

Estes resultados foram confirmados no ensaio em casa-de-vegeação, quando se quantificou o número de pústulas ao longo de oito dias, e calcularam-se os valores das áreas abaixo das curvas de progresso da doença (AACPD). Neste ensaio, observou-se efeito significativo do período de molhamento foliar e de cultivar sobre a freqüência de infecção, avaliada pelos valores de AACPD. Registrou-se, significativamente, maior progresso da ferrugem em 'Guerguera' que em 'ENA 1' e 'Souna III' (Tabela 2) e aumento das infecções com maior período de molhamento foliar (Figura 3). Observou-se, ainda, que apenas $45 \mathrm{~min}$ de molhamento foliar foram suficientes para o início do processo de infecção, o que permite concluir que este patógeno pode infectar a planta mesmo em condições mais secas, mediante a ocorrência de pequenos períodos de orvalho. Estes resultados diferem dos observados em outras ferrugens. Em alfafa (Medicago sativa L.), por exemplo, Webb \& Nutter (1997) descrevem aumento linear do número de pústulas causadas por Uromyces striatus Schröt. com o aumento do período de molhamento foliar de 4 até $24 \mathrm{~h}$. Em plantas de trigo (Triticum aestivum L.), sob condições ótimas de temperatura, $16^{\circ} \mathrm{C}$, Eversmeyer (1988) cita que $39 \%$ dos urediniósporos $P$. recondita (Roberge \& Desmazieres) germinaram em uma hora após a inoculação, e destes, $6 \%$ iniciaram o processo de infecção. $\mathrm{O}$ autor cita ainda que, a $16^{\circ} \mathrm{C}$ são necessários pelo menos $3 \mathrm{~h}$ de molhamento foliar para que se complete o processo de infecção. Para o patossistema milho (Zea mays L.) x Puccinia polysora Underw., Godoy et al. (1999) observaram que a infecção das plantas foi favorecida por temperaturas de $23^{\circ} \mathrm{C}$ e períodos de 2 a $24 \mathrm{~h}$ de molhamento foliar. Roderick \& Thomas (1997) relatam que em plantas de Lolium temulentum L. a germinação dos urediniósporos e formação de apressórios por Puccinia loliina Sydow, $P$. coronata Corda e $P$. graminis Person são favorecidos 

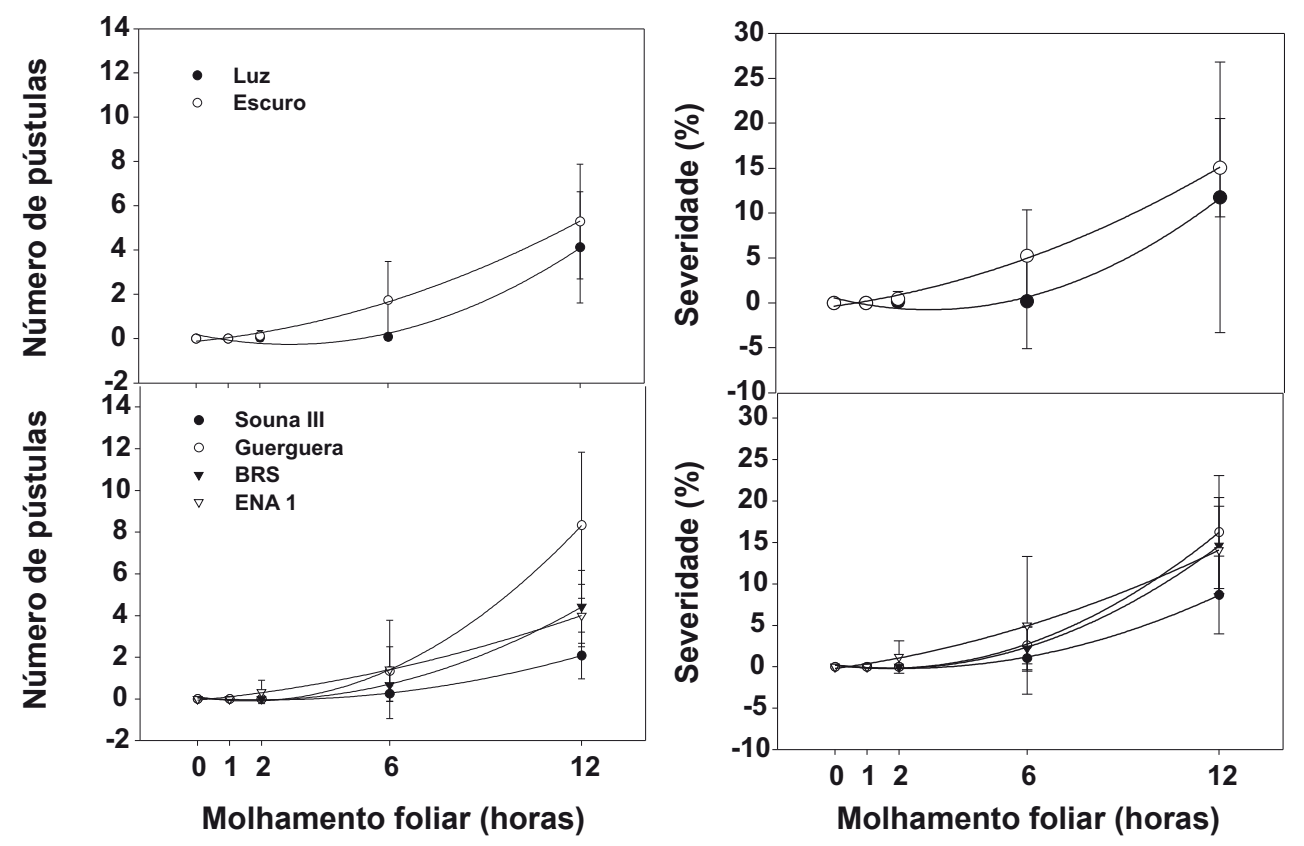

FIG. 2 - Efeito da luz e de cultivar, sob diferentes períodos de molhamento foliar, sobre o número de pústula (NP) e severidade (S) da ferrugem do milheto, causada por Puccinia substriata var. penicillariae, descritas pelo modelo quadrático, onde: A) $\mathrm{NP}_{1 \mathrm{uz}}=0,0527 \mathrm{x}^{2}-0,307 \mathrm{x}+0,190, \mathrm{r}^{2}=0,980 \mathrm{e}$ $\mathrm{NP}_{\text {escuro }}=0,0261 \mathrm{x}^{2}+0,138 \mathrm{x}-0,115, \mathrm{r}^{2}=0,995 ;$ B) $\mathrm{S}_{\text {luz }}=0,151 \mathrm{x}^{2}-0,897 \mathrm{x}+0,565, \mathrm{r}^{2}=0,978, \mathrm{~S}_{\text {escuro }}=0,066$ $\mathrm{x}^{2}-0,487 \mathrm{x}-0,375, \mathrm{r}^{2}=0,994$; C) $\mathrm{NP}_{\text {Guerguera }}=0,078 \mathrm{x}^{2}-0,251 \mathrm{x}+0,102, \mathrm{r}^{2}=0,998, \mathrm{NP}_{\mathrm{ENA} 1}=0,015 \mathrm{x}^{2}-0,149 \mathrm{x}-$ $0,061, \mathrm{r}^{2}=0,997, \mathrm{NP}_{\mathrm{BR} 1501}=0,042 \mathrm{x}^{2}-0,145 \times 0,063, \mathrm{r}^{2}=0,998$, e $\mathrm{NP}_{\text {Souna }}=0,021 \mathrm{x}^{2}-0,021 \mathrm{x}+0,044$, $\mathrm{r}^{2}=0,996$ e D) $\mathrm{S}_{\text {Guerguera }}=0,1520 \mathrm{x}^{2}-0,4895 \mathrm{x}+0,1999, \mathrm{r}^{2}=0,998, \quad \mathrm{~S}_{\mathrm{ENAl}}=0,0555 \mathrm{x}^{2}-0,5258 \mathrm{x}-0,2155, \mathrm{r}^{2}=$ $0,997, \mathrm{~S}_{\mathrm{BRS} 1501}=0,1401 \mathrm{x}^{2}-0,4829 \mathrm{x}+0,2100, \mathrm{r}^{2}=0,998$ e $_{\text {Souna }}=0,0897 \mathrm{x}^{2}-0,3725 \mathrm{x}+0,1856, \mathrm{r}^{2}=0,996$.

TABELA 2 - Efeito de cultivar sobre os valores de AACPD, calculados a partir do número de pústulas por $\mathrm{cm}^{2}$, em plantas inoculadas com urediniósporos Puccinia substriata var. penicillariae, e submetidas a diferentes períodos de molhamento foliar, em condições de casa de vegetação

\begin{tabular}{ll}
\hline \hline Cultivar & AACPD \\
\hline Guerguera & $28,52 \mathrm{a}$ \\
EN A 1 & $20,53 \mathrm{ab}$ \\
Souna III & $15,53 \mathrm{~b}$ \\
\hline CV\% & 39,52 \\
\hline${ }^{1}$ Médias seguidas pela mesma letra & minúscula na coluna, não
\end{tabular}

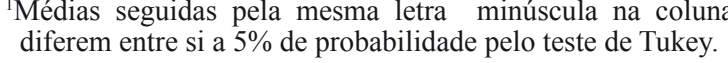

por pelo menos $5 \mathrm{~h}$ de molhamento foliar. Com base nos resultados observados no presente trabalho podese explicar o rápido progresso da ferrugem do milheto no plantio da seca no Estado do Rio de Janeiro e a habilidade do patógeno de infectar e colonizar o seu hospedeiro resultando em rápido progresso da doença sob condições favoráveis, mesmo que estas ocorram por períodos curtos. Estes resultados estão de acordo com a própria habilidade da cultura em se desenvolver sob condições áridas, conseqüentemente, sob condições pouco propícias ao desenvolvimento da maioria das doenças foliares. Assim, a ocorrência de períodos favoráveis à infecção, mesmo que estes sejam extremamente curtos, pode resultar em progresso da doença, o que reforça a necessidade de seleção de genótipos resistentes à ferrugem, para o cultivo da seca no estado do Rio de Janeiro, pois 


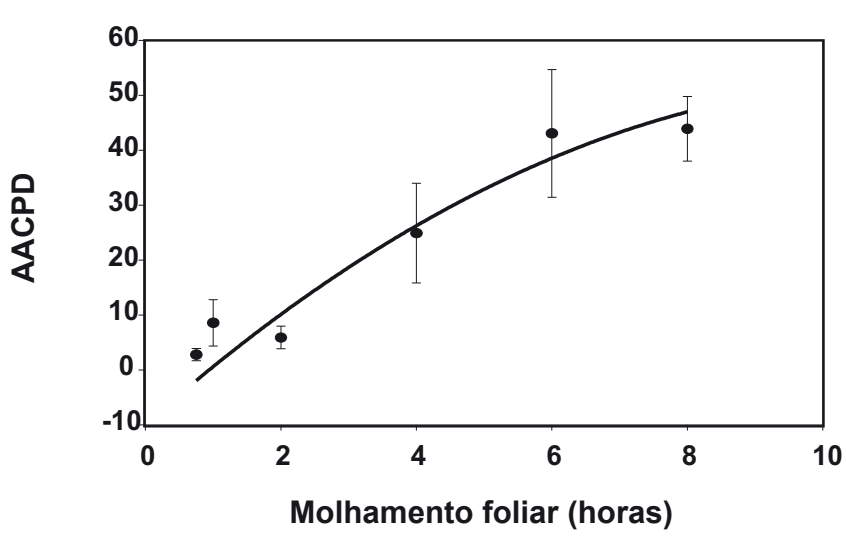

FIG. 3 - Valores de área abaixo da curva (AACPD), calculados a partir do número de pustulas. $\mathrm{cm}^{-2}$, em folhas de três cultivares de milheto inculadas com Puccinia substriata var. penicillariae, e mantidas sob diferentes períodos de molhamento foliar, ajustada pelo modelo quadrático $\left[\mathrm{Y}=-9,8866+10,9618 \mathrm{X}-0,4818 \mathrm{X}^{2} ; \mathrm{r}^{2}\right.$ $=0,998]$.

nestas condições, conforme observado por Costa (2006), a severidade da doença pode atingir níveis de 60 a 70\%, afetando de forma significativamente negativa a produção de massa seca da palhada, de massa seca total e de grãos.

\section{AGRADECIMENTOS}

$\mathrm{O}$ primeiro autor agradece ao Conselho de Aperfeiçoamento de Pessoal de Nível Superior - CAPES, pela concessão de bolsa de estudo.

\section{REFERÊNCIAS BIBLIOGRÁFICAS}

ALVAREZ, V.V.H. Avaliação da fertilidade do solo. Superfície de resposta - modelos aproximativos para expressar a relação fatorresposta. Viçosa MG. Universidade Federal de Viçosa. Imprensa Universitária. v.1. 1994.

BROWN Jr., W.M., HILL, J.P. \& VELASCO, V.R. Barley yellow rust in north america. Annual Review Phytopathology 39:367-384. 2001.

CARVALHO, A.O., SOARES, D.J., CARMO, M.G.F., COSTA, A.C.T. \& PIMENTEL, C. Description of the life-cycle of the pearl millet rust fungus - Puccinia substriata var. penicillariae with a proposal of reducing var. indica to a synonym. Mycopathologia 161:331-336. 2006

CHARCHAR, M.J.A. \& ANJOS, J.R.N. Ferrugem do milheto causada por Puccinia substriata var. penicillarie no cerrado. Fitopatologia Brasileira 27:564. 2000.

COSTA, A.C.T. Seleção de uma nova cultivar de milheto pérola, resistente à ferrugem, sob cultivo sem adubação e irrigação, semeado na época da seca. Tese de Doutorado. Seropédica RJ.
Universidade Federal Rural do Rio de Janeiro. 2006.

COSTA, A.C.T., GERALDO J., PEREIRA, M.B.P. \& PIMENTEL, C. Unidades térmicas e produtividade de genótipos de milheto semeados em duas épocas. Pesquisa Agropecuária Brasileira 40:1171-1177. 2005.

COSTA, A.C.T., GERALDO, J., OLIVEIRA, L.B., PEREIRA, M.B., CARMO, M.G.F. \& PIMENTEL, C. Variabilidade genética para caracteres de importância econômica de meios-irmãos de milheto, semeados na época da seca. Revista Brasileira de Milho e Sorgo 5:130-138. 2006.

DÍAZ-LAGO, J.E., STUTHMAN, D.D. \& LEONARD, K.J. Evaluation of components of partial resistance to oat crown rust using digital image analysis. Plant Disease 87:667-674. 2003.

EVERSMEYER, M.G. Environmental influences on the establishment of Puccinia recondita infection structures. Plant Disease 72:409-412. 1988.

GERALDO, J. Avaliação e seleção de cultivares de milheto pérola (Pennisetum glaucum (L.) R. Brown) para o plantio das águas e da seca. Tese de Doutorado. Seropédica RJ. Universidade Federal Rural do Rio de Janeiro. 2002.

GODOY, C.V., AMORIM, L. \& BERGAMIM FILHO, A. influência da duração do molhamento foliar e da temperatura no desenvolvimento da ferrugem do milho causda por Puccinia polysora. Fitopatologia Brasileira 24:160-165. 1999.

GODOY, C.V., AMORIM, L., BERGAMIN FILHO, A., SILVA, H.P., SILVA, W.J. \& BERGER, R.D. Temporal progress of southern rust in maize under different environmental conditions. Fitopatologia Brasileira 28:273-278. 2003.

HUBER, L. \& GILLESPIE, T.J. Modeling leaf wetness in relation to plant disease epidemiology. Annual Review Phytopathology 30:553-577. 1992.

KRAMER, C.L. \& EVERSMEYER, M.G. Effects of temperature on germination and germ-tube development of Puccinia recondita and $P$. graminis urediniospores. Mycological Research 96:689693. 1992.

LOPES, A.S. Diretrizes para o manejo sustentável dos solos brasileiros - região dos cerrados. Anais, 26. Congresso Brasileiro de Ciência do Solo. Rio de Janeiro RJ. CD-ROM. 1997. p.26.

NETTO, D.A.M. A cultura do milheto. Comunicado Técnico 11. Sete Lagoas MG. EMBRAPA Centro Nacional de Pesquisa de Milho e Sorgo. 1998.

NORMAN, M.J.T., PEARSON, C.J. \& SEARLE, P.G.E. Pearl millet (Pennisetum glaucum). In: Norman, M.J.T., Pearson, C.J. \& Searle, P.G.E. (Eds.) The ecology of tropical food crops. Cambridge. Cambridge University Press. 1995. pp.164-181.

PARLEVLIET, J.E. Components of resistance that reduce the rate epidemic development. Annual Review Phytopathology 17:203222. 1979.

PAYNE, W.A. Optimizing crop water use in sparse stands of pearl millet. Crop Science 92:808-814. 2000.

PEREIRA FILHO, I.A., FERREIRA, A.S., COELHO, A.M., CASELA, C.R., KARAN, D., RODRIGUES, J.A.S., CRUZ, J.C. \& WAQUIL, J.M. Manejo da cultura do milheto. Sete Lagoas MG. EMBRAPA Centro Nacional de Pesquisa de Milho e Sorgo. Circular Técnica ${ }^{\circ}$ 9. 2003.

PIMENTEL. C. Características da cultivar ENA 1 de milheto pérola 
[Pennisetum glaucum (L.) R. Brown]. Agronomia 36:62. 2002.

RODERICK, H.W. \& THOMAS, B.J. Infection of ryegrass by three rust fungi (Puccinia coronata, $P$. graminis and P. loliina) and some effects of temperature on the establishment of the disease and sporulation. Plant Pathology 46:751-761. 1997.

ROSSI, V., RACCA, P., GIOSUE, S., PANCALDI, D. \& ALBERTI, I. A simulation model for the development of brown rust epidemics in winter wheat. European Journal of Plant Pathology 103:453465. 1997.

TAPSOBA, H. \& WILSON, J.P. Effects of temperature and light on germination of urediniospores of the pearl millet rust pathogens, Puccnia substriata var. indica. Plant Disease 81:1049-1052. 1997.

VALLAVIELLE-POPE, C., GIOSUE, S., MUNK, L., NEWTON, A.C., NIKS, R.E., OSTERGARD, H., PONS-KUHNEMANN, J., ROSSI, V. \& SACHE, I. Assessment of epidemiological parameters and their use in epidemiological and forescasting models of cereal airborne diseases. Agronomie 20:715-727. 2000.

WEBB, D.H. \& NUTTER, F.W. Effects of leaf wetness duration and temperature on infection efficiency, latent period, and rate of pustule appearance of rust in alfafa. Phytopathology 87:946-950. 1997.

WILSON , J.P. \& GATES, R.N. Disease resistance and biomass stability of forage pearl milet hybrids with partial rust resistance. Plant Disease 83:733-738. 1999.

WILSON, J.P. Inheritance of partial rust resistance in pearl millet. Plant Breeding 116:239-243. 1997.

WILSON, J.P., HANNA, W.W. \& GASCHO, G.J. Pearl millet grain yield loss from rust infection. Journal of Production Agriculture 9: 543-545. 1996.

WILSON, J.P., HANNA, W.W. \& GATES, R.N. Stability of forage and quality in pearl millet hybrids heterogeneous for rust resistance. Euphytica 72:163-170. 1994. 